\title{
DEVELOPMENT OF MODELS OF SERVICE CENTER COMPANIES NETWORK ACCOMMODATION
}

\author{
Denis M. Lysanov ${ }^{1}$ \\ Anton N. Karamyshev ${ }^{2}$ \\ Ekaterina V. Abrosimova ${ }^{3}$ \\ Dmitry F. Fedorov ${ }^{4}$
}

\begin{abstract}
The density of the car service companies significantly affects the quality of services and determines the level of saturation of the market. Optimal placement of service centers allows reducing unproductive expenditures of time and money of clients for delivery of vehicles to their places of work, and thereby contributes to the increase in demand for services.
\end{abstract}

Keywords: placement of the enterprises, efficiency criterion, number of applications, power of the company, transport costs, demand for services, expenses of the enterprise, mathematical model.

\section{Introduction}

From the point of view of system approach, enterprises operating in the field of car service, are objects with certain material, labor, energy, financial, information resources and they conduct activities to address the needs of the services on maintenance and repair of vehicles. Every company can be considered as a system having a manufacturing unit and a control unit, which are in interaction with the external environment [0].

The external environment is represented by customers that have demand for services; the suppliers of components, spare parts, as well as a set of governmental, political, social and demographic conditions that influence has a significant impact on the performance of enterprises. A significant destabilizing effect on production could

\footnotetext{
${ }^{1}$ Kazan Federal University, Naberezhnye Chelny Institute

${ }^{2}$ Kazan Federal University, Naberezhnye Chelny Institute

${ }^{3}$ Kazan Federal University, Naberezhnye Chelny Institute

${ }^{4}$ Kazan Federal University, Naberezhnye Chelny Institute
} 
have a spontaneous change of demand, competitor activity, fluctuations in prices, interruptions to the recovery of resources, the failure of process equipment. Part of the destabilizing influences of the external environment can be compensated by the self sustainability of the enterprise.

Organization of work of the car service companies includes: selection and substantiation of optimum structure of production and technical base, the selection and justification of the technological scheme of work and organizational structure of the enterprise, the optimal distribution of material resources. However, whatever optimal organization options are at the design stage, they are unable to ensure the effective operation of the system in time. This is because external factors at any given point in time are random events. So you need constant regulation and control of the production process, which should ensure the most efficient operation of the enterprise [0].

The approach of the service centers to the car owners and the concentration of qualified maintenance and repair in the areas of concentration of cars presuppose the existence of a stepped system of service organization on hierarchy of which lies the idea of organizing a network of the companies of technical service with a different set of works. Organization of service presupposes the existence of companies, not just with different power, but also companies providing various types of services and the greater demand for the production of certain works, the closer must be the enterprise to consumer services, and vice versa. Meeting the demand for volume and range of services is possible if the capacity of the service centers meet the volume of demand.

The criterion of optimality of facility location for the maintenance and repair of vehicles should reflect the maximum possible saving of labor cost on the work. A necessary condition is the establishment of a system of maintenance and repair which fully satisfies the needs of car owners in all types of maintenance and repair, and the sum of the costs of the execution of these works, the transport expenses and loss of time owners waiting would be minimal $[0,0]$.

The average time of customer service directly influences the service quality and thereby affects the demand. 


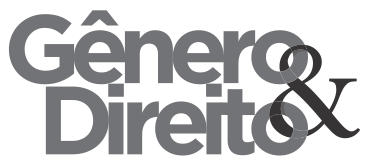

Periódico do Núcleo de Estudos e Pesquisas sobre Gênero e Direito

Centro de Ciências Jurídicas - Universidade Federal da Paraíba V. 8 - No 04 - Ano 2019 - Special Edition

ISSN | 2179-7137 |

http://periodicos.ufpb.br/ojs2/index.php/ged/index

Thus, the change of the average service time of the car owner will lead to a change in the quality of functioning of the service center system [0]. The time spent by the owner on arrival and departure from the service company, depends on the level of density of stations in the region and the operational speed of the cars. The waiting time and time spent on maintenance and repair depend on such variables as the number of applications owners and the availability of work posts in the company.

The degree of rationality of companies placing is affected by demand fluctuation factor. The average ratio of the conversion of vehicles to car service companies is 0.85 during the year. However, these appeals are unevenly distributed in time.

The probability of execution of all orders coming into the company is high in spring and summer, as the flow requirements at that time is below the capacity of car service companies. Conversely, in autumn and winter period the number of car owners who got refused of execution of the order, increases dramatically due to the fact that the capacity of service companies is insufficient to perform the required scope of work. That is why, as a variant of development of a network of service centers, there should be a mechanism of smoothing seasonal fluctuations, taking into account the aspect of rational allocation [0].

The layout of the car service company network can be obtained on the basis of the alternative approach, which considers a valid set of projects of alternative car service companies placing with different capacities, and then the optimum loading of these companies is calculated, the indicators of economic efficiency and environmental safety are evaluated.

The problem of company creation and functioning in places of cars concentration is quite complex, since its solution requires considering many different factors. However, the resolution of these issues will allow to reduce capital investments in development of material base of service businesses, but also to reduce the cost of carrying out works of maintenance and repair, as well as reduce transport costs for car owners.

\section{Methods and Models}


The solution of multiple-factor problems is rather laborious process, requiring the use of special methods, one of which is modeling. A mathematical model is linking together the most important factors of the investigated process using the system of equations.

The study of phenomena or processes mathematical methods consists of several stages [0]:

- the choice of the efficiency criterion;

- formulation of all the constraints that the best plan must satisfy;

- accumulation and processing of source information about the availability of resources and the characteristics of the production processes;

- formalization of the problem of determining a rational plan;

- construction of algorithms for solving the problem;

- calculation of the specific values of control parameters.

The issues of forecasting demand for car service are closely connected to the development of models of rational allocation of companies for maintenance and repair of vehicles.

When solving problems of development and placement of service companies one should be guided by the following main principles [0]:

- the principle of optimality, which consists in minimizing costs related to the operation of the company network for the maintenance and repair of vehicles;

- the principle of consistency, i.e. the solution of tasks in the development and deployment of not only individual companies for the maintenance and repair of vehicles, but their complexes.

Since the level of development of companies is influenced by many factors, to solve the task of the new companies for technical service vehicles it is necessary to maintain a given level of organization of the existing service network.

Several interacting companies can provide a comprehensive sectoral nodes, deployed either on one large area (complete accommodation); or in multiple venues in different cities within the economic region (scaled option); or located in one or more major areas (scatter option).

The criterion of effectiveness of the layout plan of businesses must be a compromise between the highest possible profit, amount of time 
customers waiting for the execution of the works and the cost of transporting a faulty car to the nearest service company. To meet all needs for services of maintenance and repair of vehicles, it is necessary to determine the number of service companies, their geographical location and production capacities for the implementation of the technical influences.

Let there be some region in which it is possible to allocate the deployments of cars, as well as the possible places where there are or can be built motor vehicles or car service companies. A car can be obtained for the maintenance or repair at any company from any area of the dislocation. We introduce the following notations $[0]$ :

$n$ is the number of points of concentration of vehicles $(i=1 . . n)$;

$\mathrm{m}$ is the number of possible placements of the companies rendering services to owners of vehicles $(j=1 . . m)$;

$\mathrm{X}_{\mathrm{ij}}-$ number of applications received from the $i^{\text {th }}$ item in $\mathrm{j}^{\text {th }}$ company to perform the necessary technical actions;

$Y_{j}$ - power of the $j^{\text {th }}$ company for maintenance and repair of vehicles;

$A_{i}-$ the need for technical effects cars from the $\mathrm{i}^{\text {th }}$ point of concentration;

$\mathrm{W}_{\min \mathrm{j}}$ is the minimum allowable capacity of the $\mathrm{j}^{\text {th }}$ company;

$\mathrm{W}_{\max \mathrm{j}}$ is the maximum power of the $\mathrm{j}^{\text {th }}$ company;

$\mathrm{C}_{\mathrm{ij}}$ - transport costs associated with shipping a single car from the $i^{\text {th }}$ item in $\mathrm{j}^{\text {th }}$ company for the work.

The task is to organize the work of service network in such a way as to meet the demand for services in the region and to ensure the minimum value of the cost of transporting the cars to the places of work. Taking into account the introduced notations, the mathematical model of the problem location of car service company is the following:

$$
Z=\sum_{i=1}^{n} \sum_{j=1}^{m} C_{i j} X_{i j} \rightarrow \min .
$$

Additional limitations of the model are the following:

1. Each customer's demand from the $i^{\text {th }}$ car deployment of the technical requirements should be satisfied in full:

$$
\sum_{j=1}^{m} X_{i j}=A_{i}, \quad i=\overline{1 . . n}
$$

2. The capacity of each $\mathrm{j}^{\text {th }}$ company must match the number of applications for work received from all customers: 
$\sum_{i=1}^{n} X_{i j}=Y_{j}, \quad j=\overline{1 . . m}$;

3. The capacity of each $\mathrm{j}^{\text {th }}$ company providing services of maintenance and repair is limited to the minimum and maximum of possible values:

$W_{\min j} \leq Y_{j} \leq W_{\max j}, \quad j=1 . . m ;$

4. Model variables cannot be negative:

$X_{i j}>0, Y_{j}>0, \quad i=1 . . n, j=1 . . m$

As a result of the calculations according to the model the distribution matrix of applications to carry out works between the existing service facilities and used for this production capacity are received.

The mathematical model can be taken as a basis for comparison with other models that account for various influencing factors.

The second version of the model allows to determine the rational plan of the location of the existing service companies with a cost effective organization of production and the necessary types of work. The source of information for this research is data on needs in technical effects of customers and specific features of development costs and manufacturing performance.

The total cost function for the reconstruction of buildings, technical reequipment of the power production can be written in the form $\mathrm{F}_{\text {Пть }}(\mathrm{Y})$.

The total cost function to conduct the necessary technical impacts on service vehicles which are included in the cost of operations depending on the capacity of the enterprise is expressed by the following dependence $\mathrm{F}_{\mathrm{a}}(\mathrm{Y})$.

For further analysis it is necessary to consider all possible locations of the service providers in the region. For each of the region development options are set in a number of capacities, representing a fixed number of technical impacts of each species. Knowing the places of car concentration and the planned facility locations the transportation costs matrix $\mathrm{C}$ is determined. Then the restrictions on capacity of each company for any kind of technical impacts are subjected - values $\mathrm{W}_{\min \_j}$ and $\mathrm{W}_{\max \_j}$. Choosing numerical values of the capacities, consider the maximum possible development of company (by size of territory, availability of workers, technological equipment).

It is required to determine the use 
of existing facilities and service companies to meet the needs of car owners in the implementation of all kinds of technical effects, and the amount of transport expenses, expenses for reconstruction and re-equipment of production, the cost of the necessary types of works would be minimal. The objective function of a described task may be presented in the form of the following functions: perform technical impact and possible value of the lost profits associated with downtime of the vehicle while performing the necessary work. The source of information for this area of research is data on needs in technical effects, production costs functions, transport costs for delivery vehicles and maximum capacity of each company.

It is necessary to define such an option and specialization of existing
The presented version of the research can also be used in situations when there are no functioning service companies in the region and it is necessary to decide the question of their creation.

The third variant of the model in addition to the considered factors takes into account the cost of car owners to
$\left(Y_{j}\right) \rightarrow$ min owners in the implementation of all types of technical impacts and the amount of the costs of reconstruction and reequipment of production, the amount of expenses for works, the amount of transportation costs and the amount of time losses of car owners while waiting the execution of works in monetary terms would be minimal.

Thus, it is necessary to minimize the following function:

$$
Z=\sum_{i=1}^{n} \sum_{j=1}^{m} C_{i j} X_{i j}+\sum_{j=1}^{m} F_{\text {ПТБ }}\left(Y_{j}\right)+\sum_{j=1}^{m} F_{a}\left(Y_{j}\right)+\sum_{i=1}^{n} \sum_{j=1}^{m} T_{i} C w_{j} X_{i j}+\sum_{i=1}^{n} \sum_{j=1}^{m} \frac{T_{i}}{P_{j}} C a X_{i j},
$$

Where $T_{i}$ is the average complexity of execution of work on one car from the $\mathrm{i}^{\text {th }}$ point of dislocation;

$\mathrm{Cw}_{\mathrm{j}}$ - the average cost of 1 person in hour of work on the $\mathrm{j}^{\text {th }}$ enterprise;
$P_{j}-$ the number of production workers simultaneously working on the same post;

$\mathrm{Ca}-$ cost of 1 hour of transport vehicle operation. 
The latest model of the problem represents the most general mathematical model of allocation and development of network service businesses.

As additional restrictions on the range of possible solutions to the considered problem can be restrictions on the use of space and labor [Erro! Fonte de referência não encontrada.].

For the organization of the production process a certain area is required. Therefore, knowing the value of the square of a certain company, you can determine the maximum possible power in the organization of any technological process:

$$
\sum_{j=1}^{m} F S\left(Y_{j}\right) \leq S
$$

where $F s\left(Y_{j}\right)$ is a function of the required space for the organization of works at the $\mathrm{j}^{\text {th }}$ company.

The work of the enterprises can be arranged in the same area with different number of shifts, and this will increase their power. In these conditions the number of employed workers will increase. Therefore, in the model the restriction of the use of human resources can be used:

$$
\sum_{j=1}^{m} F p\left(Y_{j}\right) \leq P,
$$

where $F p\left(Y_{j}\right)$ is the dependence of the number of workers required for the organization of works on the $\mathrm{j}^{\text {th }}$ service company from power.

\section{Conclusions}

Final layout of the network service companies can be obtained on the basis of the alternative approach, in which a valid set of projects of placing companies with different capacities is considered. Then the load of these companies and the value performance criteria for each accommodation are calculated. When solving this problem, the situation of incompatibility of system limitations may arise, for example, the designed capacity of the company obviously can not meet the high requirements of customers in service and repair of vehicles.

There are two options in this case:

1) search for additional opportunities to increase production capacities (additional investment);

2) artificial fixation of a certain level of satisfaction in services.

\section{Acknowledgements}


The work is performed according to the Russian Government Program of Competitive Growth of Kazan Federal University.

\section{References}

Lysanov D.M., Nazmutdinov A.M. The demand and operation of car service centers// International Journal of Applied Engineering Research, 2016. Volume 11, Number 6, pp. 4314-4317.

Lysanov D.M., Utyaganov R.F. Criteria for evaluating the effectiveness of car service companies// International Journal of Applied Engineering Research, 2016. Volume 11, Number 20, pp. 10190-10191.

Mirotin L. B. Car service management. M.: Examination, 2004. 320 p.

Cabaniss Jr., J.M., Gorman, C., Juchno,

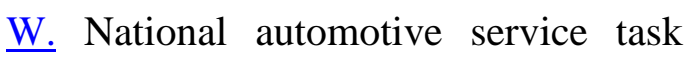
force: A case study of industry collaboration to improve serviceability by resolving gaps in vehicle service and tool information SAE Technical Papers, 2008.
Leyland S. Mat. Customers are king Transp. 1991, №4469 - 1. P. 137.

.Lysanov D.M., Utyaganov R.F. Methodological basis for the rational development of car service// International Journal of Applied Engineering Research, 2015. Volume 10, Number 22, pp. 43063-43065.

Egorova N.E., Mudunov A.S. Service Station. Models and methods of forecasting activities. M.: Exam, 2002. $256 \mathrm{p}$.

Bagrinovskiy K. A., Egorova N. E. Simulation systems in the planning of economic objects. M.: Nauka, 1980. 238 p.

Lyasko V.I., Prudovskiy B.D. Optimizing the placement of the enterprises of technical maintenance and repair of rolling stock. M.: Transport, 1977. 198 p.

Kartashov V. P., Development of industrial and technical base of motor transport companies. M.: Transport, 1991. $151 \mathrm{p}$ 